\title{
Isovolumic contraction time of right ventricle in d-transposition
}

Sir,

I read with interest the recent letter by Spodick concerning the function of the editorial board of the British Heart fournal as guardians of the English tongue. I further noted that in the editorial reply to Dr Spodick it was stated that the Journal was committed to do its best to avoid offensive neologisms. I would suggest that already evidence is accruing that the best is not good enough. I refer specifically to the use of the offensive neologism "d-transposition" to describe the congenital malformation characterised by the combination of atrioventricular concordance and ventriculoarterial discordance ( $\mathrm{Br}$ Heart $\mathcal{F}$ 1980; 44: 204-7). Reading this paper it is very evident that the authors are describing the anomaly which can conveniently be termed "complete transposition." By using the neologism "dtransposition," however, one is left with several queries. Do the authors refer to all those patients who have transposition of the great arteries with the aorta in the right-sided position? One thinks not since they state in their paper that their patients have received a Mustard procedure. Do they refer only to those patients with "complete transposition" in which the aorta is to the right of the pulmonary trunk? Again, one thinks not, since this would exclude the majority of patients who had situs inversus but, more importantly, approximately $\mathbf{4 0 \%}$ of the patients who had complete transposition and situs solitus. I would therefore submit that the use of "d-transposition" is greatly to be deplored and would suggest that it is a neologism to be avoided. R H Anderson,

Cardiothoracic Institute, Fulham Road, Brompton, London SW3 6HP.

Sir,

The conclusion by Fouron et al. ${ }^{1}$ that prolongation of the right ventricular pre-ejection period in d-transposition of the great arteries is due not to lengthening of isovolumic contraction time but to delay in the onset of right ventricular contraction, rests on their demonstration of unexpectedly late tricuspid valve closure. An alternative explanation for this finding should be considered.

The timing of atrioventricular valve closure is determined only in part by the onset of ventricular contraction; in patients with sinus rhythm a critical factor is atrial contraction and relaxation, of which a direct consequence is the profound influence of the PR interval on the timing of mitral and tricuspid closure (and loudness of the first heart sound). ${ }^{2}$ When atrial contraction is absent as in atrial fibrillation, ${ }^{3}$ or weak, ${ }^{45}$ the tendency for apposition of the valve leaflets to occur before the start of ventricular contraction is diminished or absent, so that closure occurs from a wide open position and is completed later after the onset of contraction (and of electrical depolarisation) than in subjects with normal atrial contraction and $\mathrm{P} P \mathrm{P}$ interval in the physiological range. Operative rerouting of the venous return in d-transposition requires a long right atrial incision, and it is easy to imagine that this, together with the intracardiac repair, might result in impairment of atrial contraction and consequent late tricuspid closure despite a right ventricular contraction beginning at the normal time. Some of the patients may, indeed, have developed atrial fibrillation. Inspection of the published figure gives some support for this argument: the anterior tricuspid leaflet shows surprisingly little anterior movement after atrial contraction, and the final rapid closing movement clearly starts with the leaflets widely separated. If the authors' explanation for the delayed closure is correct, we would expect to see gradual apposition of the valve leaflets with a final rapid phase corresponding to the delayed ventricular contraction.

Though the isovolumic contraction time is often defined as the period in early systole while both inflow and outflow valves are closed, atrioventricular valve closure usually occurs after the beginning of tension development in its respective ventricle and the time relation of these two events is complicated. Deductions on the rate of pressure development in the ventricle based on the duration of the isovolumic contraction time defined in this way should, therefore, be made with circumspection.

Nicholas Brooks,
The London Chest Hospital,
Bonner Road, London E2 9JX.

\section{References}

1 Fouron J-C, Vallot F, Bourlon F, Lombaert $M$, Ducharme G, Davignon A. Isovolumic contraction time of right ventricle in d-transposition of great arteries. $\mathrm{Br}$ Heart f 1980; 44: 204-7. 
2 Brooks N, Leech G, Leatham A. Factors responsible for normal splitting of the first heart sound. High-speed echophonocardiographic study of valve movement. Br Heart $\mathcal{F}$ 1979; 42: 695-702.

3 Brooks $\mathrm{N}$. The intensity and splitting of the first heart sound. A study using simultaneous echo- and phonocardiography in normal subjects and patients with bundlebranch block. University of London: MD Thesis, 1978: 73.

4 Little RC, Hilton JG, Schaefer RD. The first heart sound in normal and ectopic ventricular contractions. Mechanism of closure of the A-V valves. Circ Res 1954; 2: 48-52.

5 Sarnoff SJ, Gilmore JP, Mitchell JH. Influence of atrial contraction and relaxation on closure of mitral valve. Observations on effects of autonomic nerve activity. Circ Res 1962; 11: 26-35:

These two letters were shown to Drs Fouron and Davignon who reply as follows:

\section{Reply to Professor R H Anderson}

Controversy over terminology of complex congenital heart diseases is, and most likely will remain, a frequent subject of letters to editors of medical journals.

In his letter, Professor R $\mathrm{H}$ Anderson deplores the use of "d-transposition" (d-TGA) in our article on isovolumic contraction time of the right ventricle. ${ }^{1} \mathrm{He}$ favours the term "complete transposition." Like the majority of paediatric cardiologists, ${ }^{2}$ we have adopted the segment-by-segment approach to the diagnosis of congenital heart disease as suggested by Van Praagh, ${ }^{3}$ because this is the only approach that applies accurately in all situations.

d-TGA is neither offensive, nor neologistic. Since Anderson uses the term TGA himself, one must assume that he is objecting to the prefix $d$. $d$ is a well established abbreviation for dextro, which of course is a Latin word meaning right, as in dextrocardia. It is difficult to agree with Anderson that the Latin term dextro $(D)$ is a new term (neologism). Indeed, by comparison with dextro, most of the English language is neologistic.

Regarding Anderson's questions, d-TGA refers to all cases of TGA in which the aortic valve lies to the right (dextro or d) relative to the pulmonary valve. All of our cases of d-TGA had situs solitus of the viscera and atria (S) and a d-loop (d), that is TGA $\{s, d, d\}$. When d-TGA is used without further qualification, the typical situation-TGA $\{\mathbf{s}, \mathrm{d}, \mathrm{d}\}$-is meant, as in our patients and as in $95 \%$ of necropsied cases. Hence, d-TGA is convenient shorthand.

"Complete" TGA has come to mean physiologically uncorrected TGA. Thus, complete TGA is a physiological designation. There are several anatomical types of complete TGA. The aortic valve can lie directly anterior to the pulmonary valve, that is TGA $\{S, D, A\}$, in $1 \%$ of necropsied cases. Or the aortic valve can lie to the left of the pulmonary valve, that is TGA $\{S, D, L\}$, as in $3 \%$ of necropsied cases-far less than Anderson's figure of "approximately $40 \%$."

From the clinical standpoint, therefore, the physiological category of complete (physiologically uncorrected) TGA can be rendered anatomically precise by segment-by-segment analysis and terminology, as above. Anatomical precision is important physiologically and surgically. The segmental approach to the diagnosis of congenital heart disease applies accurately in all anomalies, no matter how complex. This is why most paediatric cardiologists are now using the segmental approach and terminology, of which d-TGA is part.

\section{References}

1 Fouron J-C, Vallot F, Bourlon F, Lombaert $M$, Ducharme G, Davignon A. Isovolumic contraction time of right ventricle in d-transposition of great arteries. Br Heart F 1980; 44: 204-7.

2 Stanger P, Rudolph AM, Edwards JE. Cardiac malpositions. An overview based on study of sixty-five necropsy specimens. Circulation 1977; 56: 159-72.

3 Van Praagh R. Terminology of congenital heart disease. Glossary and commentary. Circulation 1977; 56: 139-143.

\section{Reply to Dr Nicholas Brooks:}

In his letter, Dr Brooks considers an abnormal delay in tricuspid valve closure as an alternative explanation for the longer electromechanical delay (EMD) of the right ventricle in d-TGA. If this were the case, the isometric contraction time (ICT) would have been abnormally shorter, and the sum of EMD and ICT, that is the PEP, would be normal. This is not what we found.

Although we fully agree with the theoretical possibilities put forward by Dr Brooks to explain a late tricuspid closure, none of these was present in our group of patients: the PR interval was normal and there was no atrial fibrillation. Furthermore, late closure of the tricuspid valve has never been described in complete transposition of the great arteries, neither before nor after Mustard operation. ${ }^{1}$

Jean-Claude Fouron,
André Davignon,
Section of Cardiology,
Department of Pediatrics,
Sainte-Justine Hospital,
Montreal, Canada.

\section{Reference}

1 Milner S, Meyer RA, Venables AW, Korfhagen J, Kaplan S. Mitral and tricuspid valve closure in congenital heart disease. Circulation 1976; 53: 513-8. 